\title{
Lung Collapse Secondary to Massive Pericardial Effusion in Adults: Two Case Reports
}

\author{
Yogesh Manhas, Antara Gokhale \\ Department of Critical Care, Royal Hospital, Muscat, Oman
}

\section{Abstract}

We present two cases of respiratory insufficiency due to left lung collapse secondary to massive pericardial effusion. Both patients had pericardial effusion due to their underlying disease. Radioimaging showed compression of the left bronchus. Patients got symptomatic relief after pericardiocentesis. Follow-up imaging showed expansion of the lung.

Keywords: Lung collapse, pericardial effusion, pericardiocentesis

\section{INTRODUCTION}

Obstruction of bronchus internally or externally can cause lung collapse. Rapidly developing lung collapse causes pain, dyspnea, and cyanosis. Symptoms may be mild or absent if collapse develops slowly. Slowly developing pericardial effusion is often asymptomatic.

Literature search did not show cases of lung collapse due to pressure of pericardial effusion in adults. The bronchus in adults is more cartilaginous and does not collapse easily.

We present two cases that developed left lung collapse due to massive pericardial effusion. The first patient had long-standing hypothyroidism with noncompliance to treatment. The other patient had hereditary hemorrhagic telangiectasia (HHT) and liver cirrhosis. Radioimaging and electrocardiography (ECHO) confirmed diagnosis. Pericardiocentesis improved the clinical and radiological picture.

\section{Case Reports}

\section{Case 1}

A 42-year-old female with 8-year history of hypothyroidism, noncompliant to medications presented to the emergency department with shortness of breath and increased daytime somnolence.

She was afebrile, drowsy, tachypneic, and using accessory muscles of breathing. Heart rate and blood pressure was 68/

\begin{tabular}{|l|l|}
\hline \multicolumn{3}{c|}{ Access this article online } \\
\hline Quick Response Code: & Website: \\
& www.ijccm.org \\
& \\
&
\end{tabular}

min and 112/60 $\mathrm{mmHg}$ respectively with room air saturation of $74 \%$. Systemic examination showed decreased chest wall movement and absent air entry on left side. There was no jugular venous distension, pulses paradoxus, or pericardial rub.

Electrocardiogram (ECG) showed sinus rhythm and low voltage complexes. Chest X-ray (CXR) revealed white out of left side [Figure 1].

Laboratory investigation revealed the following: arterial blood gas showed $\mathrm{PaCo}_{2}-76 \mathrm{mmHg}, \mathrm{PaO}_{2}-58 \mathrm{mmHg}$ and $\mathrm{pH}-7.20$, hemoglobin $6.2 \mathrm{~g} / \mathrm{dl}$, white cell count - $5.6 \times 109$ / 1, sodium - $122 \mathrm{mmol} / \mathrm{L}$; potassium $4.6 \mathrm{mmol} / \mathrm{L}$, TSH - 212 mIU/L (Normal: $0.35-5 \mathrm{mIU} / \mathrm{L})$.

Noninvasive ventilation (NIV) was initiated with BiPAP mode (IPAP/EPAP-12/6, Fio $_{2} 40 \%$ ) to support respiration. Computerized tomogram (CT) scan showed a large pericardial effusion measuring $3.5 \mathrm{~cm}$ thickness compressing left main bronchus causing almost complete collapse of the left lung [Figure 2]. Echocardiography (ECHO) confirmed large pericardial effusion with no signs of tamponade.

As the patient did not improve with NIV, decision was made to perform pericardiocentesis to relieve compression of left

Address for correspondence: Dr. Antara Gokhale, Department of Critical Care, Royal Hospital, Muscat, Oman. E-mail: gokhaleantara@gmail.com

This is an open access article distributed under the terms of the Creative Commons Attribution-NonCommercial-ShareAlike 3.0 License, which allows others to remix, tweak, and build upon the work non-commercially, as long as the author is credited and the new creations are licensed under the identical terms.

For reprints contact: reprints@medknow.com

How to cite this article: Manhas Y, Gokhale A. Lung collapse secondary to massive pericardial effusion in adults: Two case reports. Indian J Crit Care Med 2018;22:191-4. 
bronchus. Five hundred milliliter of clear pericardial fluid was drained under ECHO using pigtail catheter. Eight hundred milliliter was drained over the next $24 \mathrm{~h}$. The patient got immediate symptomatic relief. Repeat CXR showed lung expansion [Figure 3].

She was successfully weaned from NIV in the next few hours and discharged from the Intensive Care Unit within $24 \mathrm{~h}$ with thyroid supplementation.

\section{Case 2}

A 54-year-old male known case of HTT, chronic hepatitis B, and chronic anemia was admitted with bleeding per rectum.

On examination, he was conscious, oriented, emaciated, and pale. Clinical examination revealed decreased air entry on left side, muffled heart sounds, and abdominal distension with ascites. He was hemodynamically stable.

Investigations revealed hemoglobin $-1.4 \mathrm{~g} / \mathrm{dl}$, platelets -224 x $10^{9} / 1, \mathrm{WBC}-4.6$ x 109/1, INR - 1.25 , sodium - $136 \mathrm{mmol} / \mathrm{L}$, potassium - $4.4 \mathrm{mmol} / \mathrm{L}$, serum creatinine $-99 \mu \mathrm{mol} / \mathrm{l}$, ECG - sinus rhythm and low voltage complexes.

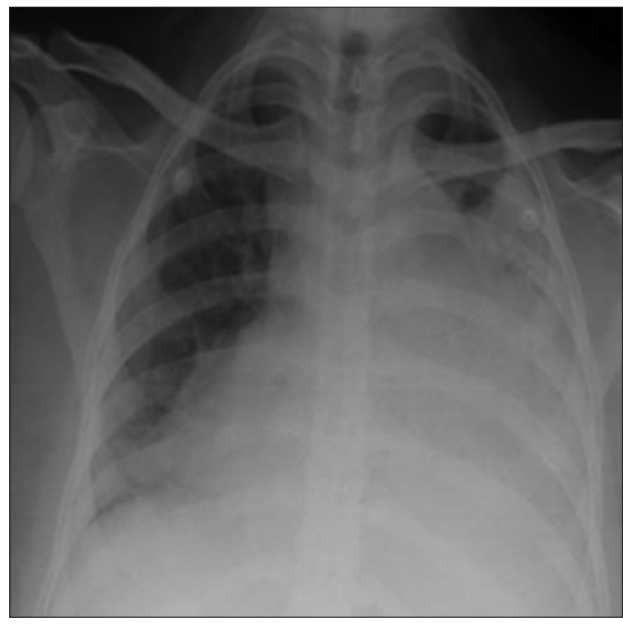

Figure 1: Case 1: Cardiomegaly with left lung collapse in case of hypothyroidism

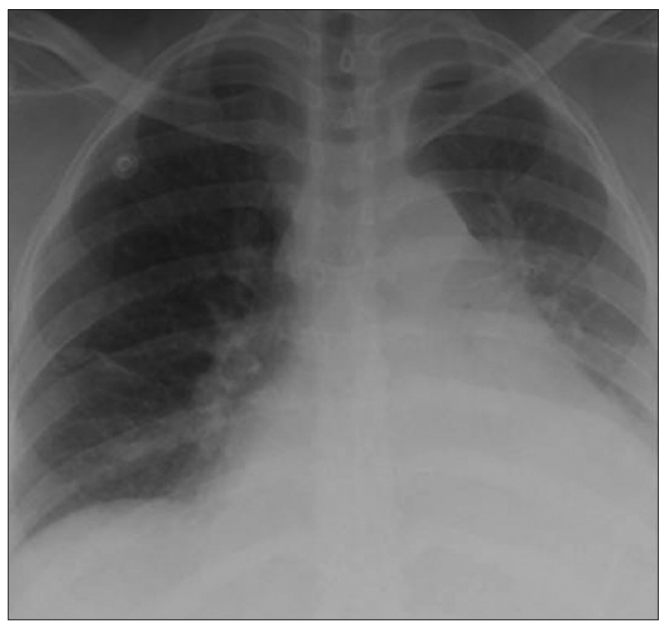

Figure 3: Case 1: Expansion of left lung after pericardiocentesis
CXR revealed increased cardiac shadow with loss of left lung volume [Figure 4].

Chest CT demonstrated large pericardial effusion compressing left bronchus causing collapse of the left lung [Figure 5]. Echocardiography showed massive pericardial effusion measuring $5.4 \times 5.1 \times 4.3$ with right atrium diastolic collapse.

Pericardiocentesis was performed to relieve compressing effect of effusion on heart and lung. Under echocardiography guidance, $800 \mathrm{ml}$ of fluid drained. 3-3.5 L of fluid was daily drained over the next few days. Since repeat ECHO showed persistent pericardial effusion, the patient underwent left pleuropericardial window. The subsequent radioimages showed expansion of the left lung [Figures 6 and 7].

\section{Discussion}

The heart is enclosed in a fibro serous sac-pericardium and contains about $50 \mathrm{ml}$ of serous fluid. Pericardial effusion can be due to variety of causes.

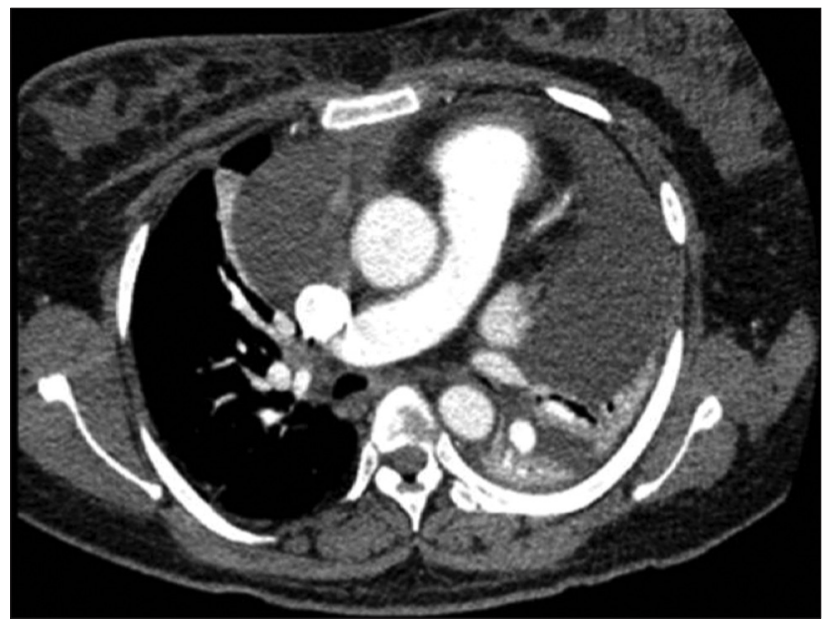

Figure 2: Computerized tomogram chest of patient with hypothyroidism showing complete obliteration of left main bronchus

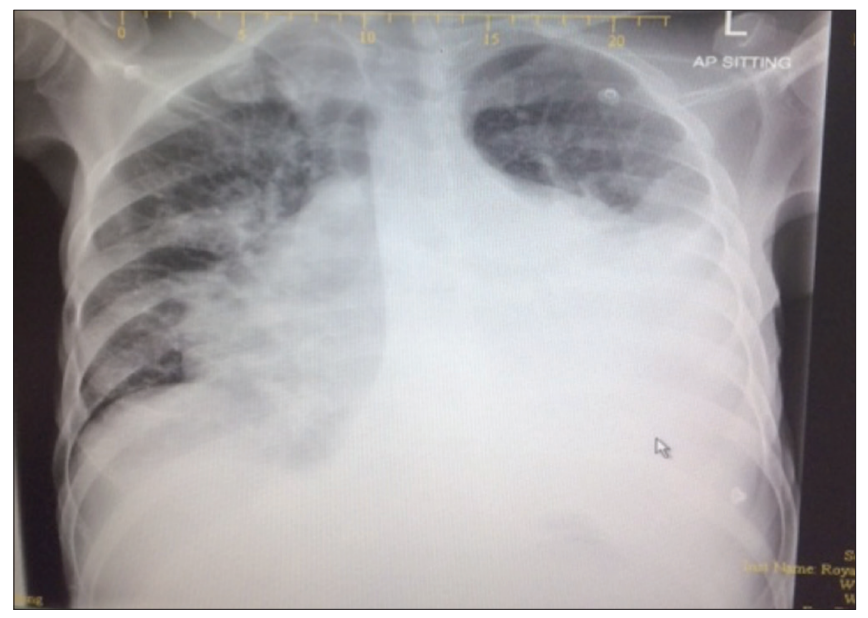

Figure 4: Chest X-ray of Case 2: Patient with hereditary hemorrhagic telangiectasia with cardiomegaly and left lung collapse 


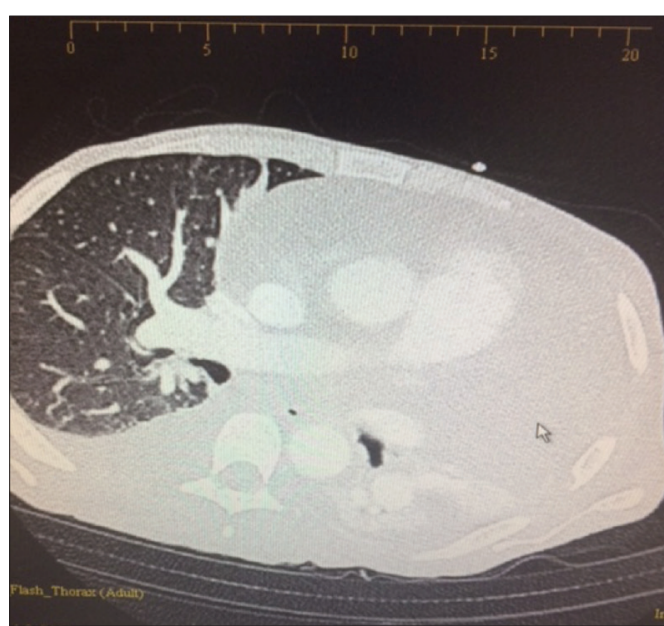

Figure 5: Computerized tomogram chest of Patient 2 with hereditary hemorrhagic telangiectasia showing complete obliteration of left main bronchus

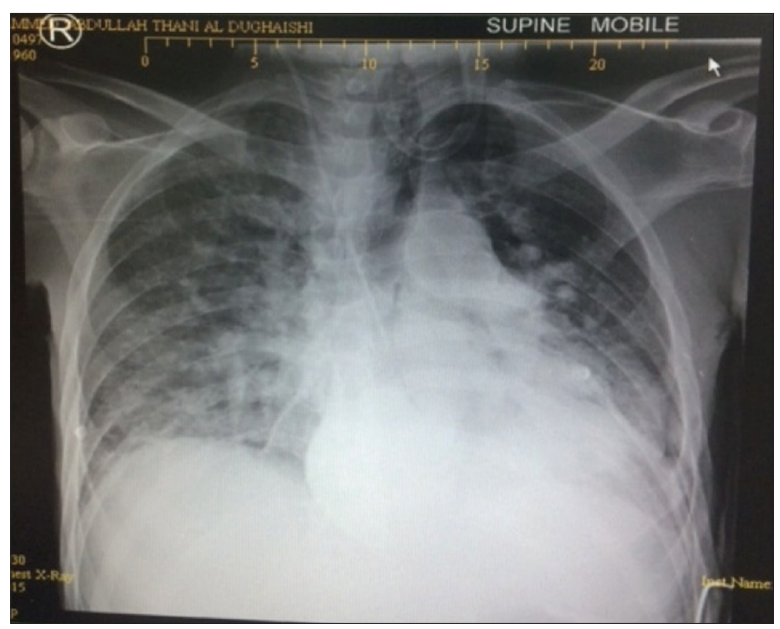

Figure 6: Chest X-ray of patients with hereditary hemorrhagic telangiectasia showing partial expansion of left lung after pericardiocentesis

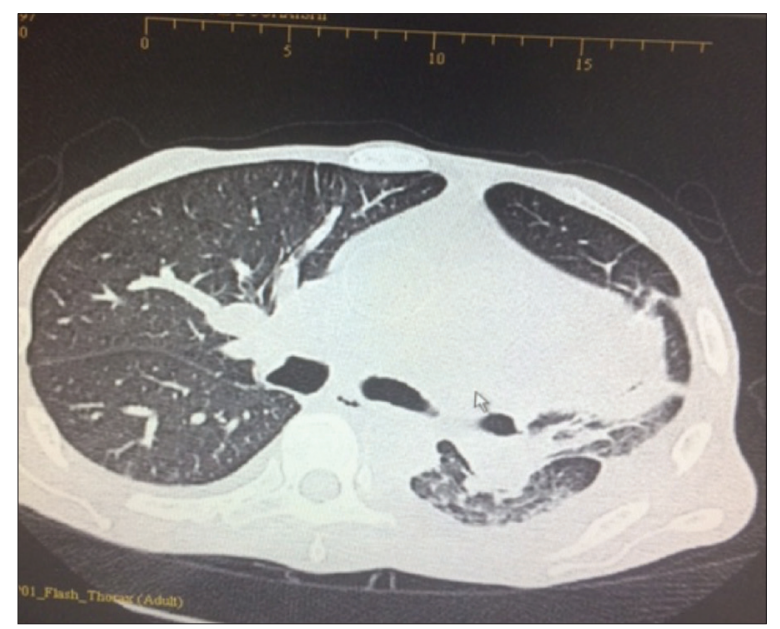

Figure 7: Computerized tomogram chest in patient with hereditary hemorrhagic telangiectasia after pericardiocentesis showing partial opening of the left main bronchus
Congestive cardiac failure, nephrotic syndrome, cirrhosis, and protein malnutrition cause serous effusion. Bloody effusions are common in acute myocardial infarction, malignancies, postcardiac surgery, anticoagulant use, and chronic renal disease. ${ }^{[1]}$ Injury to thoracic duct results in chylous effusion. ${ }^{[2]}$ Tuberculosis, Coxsackie B virus, and bacterial infections cause effusion.

Clinical presentation depends on the etiology and rate of fluid collection. Rapid accumulation leads to dramatic symptoms of cardiac tamponade. Slowly accumulating pericardial fluid allows large effusions to collect over time before a significant increase in pressure occurs to cause symptoms. ${ }^{[3]}$ Often, these effusions are drained to relieve cardiac tamponade.

About 3\%-6\% of patient with hypothyroidism develop pericardial effusion. It is commonly seen if the disease is not adequately controlled with medications. ${ }^{[4]}$ Increased systemic capillary permeability, disturbances in electrolytes, and lipid metabolism are the proposed mechanisms. ${ }^{[5]}$ These patients are often asymptomatic, and effusion is discovered on routine investigations. Treatment is thyroxin supplementation, and only a small number of patients who present with cardiac tamponade require pericardiocentesis. ${ }^{[5,6]}$ First patient presented with a large pericardial effusion without cardiac tamponade but rather an unusual presentation of lung collapse due to compression of left bronchus which required pericardiocentesis.

HHT is an autosomal dominant-inherited disorder characterized by vascular malformations predominantly in the brain, liver, and lungs. Patients present with hemorrhages causing anemia and organ-related symptoms such as stroke, pulmonary, and portal hypertension. ${ }^{[7]}$ Our patient had vascular malformations involving the entire gastrointestinal tract and liver cirrhosis causing repeated GI bleed, portal hypertension, and ascites. He presented with breathlessness that was initially attributed anemia. Persistence of symptoms after correction of anemia, evidence of cardiomegaly, and left-sided haziness on CXR led to echocardiography and CT scan examination that showed significant pericardial effusion. There was no pleural effusion.

Hemorrhagic pericardial effusion has been described in patients with HHT. ${ }^{[8]}$ Our case did not have a hemorrhagic effusion. Cirrhosis and associated hypoalbuminemia could have resulted in an effusion. Though the echocardiography showed right atrial collapse, there was no hemodynamic instability suggesting tamponade. Chest CT revealed compression of left bronchus with collapse.

In both cases, pericardiocentesis was done to relieve compression on left bronchus. Both patients showed clinical and radiological evidence of improvement after pericardiocentesis.

The heart is situated more in the left side of thorax in the middle mediastinum. Left main bronchus is twice the length of right bronchus and more horizontally placed. Its anatomical relation to heart in the mediastinum makes it more prone to compression by the enlarging pericardial effusion. There are 
reports of left bronchus compression by enlarged left atrium, pulmonary artery, and lymph nodes in children. ${ }^{[9,10]}$

Literature search did not show reports of pericardial effusion causing lung collapse in adults.

Left lung expanded completely in the first case and partially in the second patient who required pleuropericardial window creation.

\section{Conclusion}

Long-standing massive pericardial effusion can cause compression of bronchus leading to lung collapse in adults. Anatomical location of the left main bronchus makes it more susceptible to collapse. Pericardiocentesis can give symptomatic relief to patients with respiratory insufficiency with radiological evidence of compression.

\section{Declaration of patient consent}

The authors certify that they have obtained all appropriate patient consent forms. In the form the patient(s) has/have given his/her/their consent for his/her/their images and other clinical information to be reported in the journal. The patients understand that their names and initials will not be published and due efforts will be made to conceal their identity, but anonymity cannot be guaranteed.

\section{Financial support and sponsorship}

Nil.

\section{Conflicts of interest}

There are no conflicts of interest.

\section{References}

1. Roberts WC. Pericardial heart disease: Its morphologic features and its causes. Proc (Bayl Univ Med Cent) 2005;18:38-55.

2. Hawker RE, Cartmill TB, Celermajer JM, Bowdler JD. Chylous pericardial effusion complicating aorta-right pulmonary artery anastomosis. J Thorac Cardiovasc Surg 1972;63:491-4.

3. Shabetai R. Pericardial effusion: Haemodynamic spectrum. Heart 2004;90:255-6.

4. Kabadi UM, Kumar SP. Pericardial effusion in primary hypothyroidism. Am Heart J 1990;120:1393-5.

5. Patil VC, Patil HV, Agrawal V, Patil S. Cardiac tamponade in a patient with primary hypothyroidism. Indian $\mathrm{J}$ Endocrinol Metab 2011;15:S144-6.

6. Apaydin M, Beysel S, Demirci T, Caliskan M, Kizilgul M, Ozcelik O, et al. A case of primary hypothyroidism initially presenting with massive pericardial effusion. J Clin Transl Endocrinol 2016;2:1-2.

7. Govani FS, Shovlin CL. Hereditary haemorrhagic telangiectasia: A clinical and scientific review. Eur J Hum Genet 2009;17:860-71.

8. Kanna B, Das B. Hemorrhagic pericardial effusion causing pericardial tamponade in hereditary hemorrhagic telangiectasia. Am J Med Sci 2004;327:149-51.

9. Dailey ME, O'Laughlin MP, Smith RJ. Airway compression secondary to left atrial enlargement and increased pulmonary artery pressure. Int J Pediatr Otorhinolaryngol 1990;19:33-44.

10. Jaijee SK, Ariff B, Howard L, O'Regan DP, Gin-Sing W, Davies R, et al. Left main bronchus compression due to main pulmonary artery dilatation in pulmonary hypertension: Two case reports. Pulm Circ 2015;5:723-5. 